ARTICLE

\title{
Structural basis of the ligand binding and signaling mechanism of melatonin receptors
}

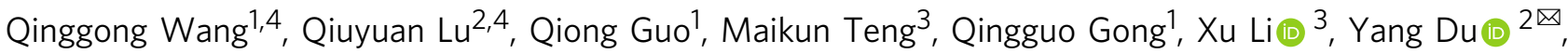 \\ Zheng Liu (1D ${ }^{2 凶} \&$ Yuyong Tao (1D ${ }^{1 凶}$
}

Melatonin receptors ( $\mathrm{MT}_{1}$ and $\mathrm{MT}_{2}$ in humans) are family $\mathrm{A} G$ protein-coupled receptors that respond to the neurohormone melatonin to regulate circadian rhythm and sleep. Numerous efforts have been made to develop drugs targeting melatonin receptors for the treatment of insomnia, circadian rhythm disorder, and cancer. However, designing subtypeselective melatonergic drugs remains challenging. Here, we report the cryo-EM structures of the $\mathrm{MT}_{1}-\mathrm{G}_{i}$ signaling complex with 2-iodomelatonin and ramelteon and the $\mathrm{MT}_{2}-\mathrm{G}_{i}$ signaling complex with ramelteon. These structures, together with the reported functional data, reveal that although $\mathrm{MT}_{1}$ and $\mathrm{MT}_{2}$ possess highly similar orthosteric ligand-binding pockets, they also display distinctive features that could be targeted to design subtype-selective drugs. The unique structural motifs in $\mathrm{MT}_{1}$ and $\mathrm{MT}_{2}$ mediate structural rearrangements with a particularly wide opening on the cytoplasmic side. $G_{i}$ is engaged in the receptor core shared by $M T_{1}$ and $M T_{2}$ and presents a conformation deviating from those in other $G_{i}$ complexes. Together, our results provide new clues for designing melatonergic drugs and further insights into understanding the $\mathrm{G}$ protein coupling mechanism.

\footnotetext{
${ }^{1}$ Department of Clinical Laboratory, The First Affiliated Hospital of USTC, Ministry of Education Key Laboratory for Membraneless Organelles \& Cellular Dynamics, Biomedical Sciences and Health Laboratory of Anhui Province, School of Life Sciences, Division of Life Sciences and Medicine, University of Science and Technology of China, 230027 Hefei, P.R. China. ${ }^{2}$ Kobilka Institute of Innovative Drug Discovery, School of Life and Health Sciences, Chinese University of Hong Kong, 518172 Shenzhen, Guangdong, China. ${ }^{3}$ Ministry of Education Key Laboratory for Membraneless Organelles \& Cellular Dynamics, Biomedical Sciences and Health Laboratory of Anhui Province, School of Life Sciences, Division of Life Sciences and Medicine, University of Science and

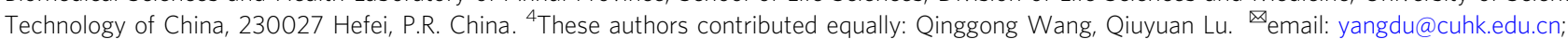
liuzheng@cuhk.edu.cn; taoyy@ustc.edu.cn
} 
$\mathrm{M}$ elatonin receptors (MTs) are family A G proteincoupled receptors (GPCRs) expressed in the central nervous system (CNS) and peripheral tissues and are targets for melatonin, the major neurohormone involved in circadian rhythm and sleep regulation ${ }^{1-3}$. In vertebrates, melatonin (N-acetyl-5-methoxytryptamine) is mainly synthesized in the pineal gland and follows a circadian pattern synchronized to the dark phase of the natural light/dark cycle ${ }^{4,5}$. Modern life, such as worldwide travel, shift work, and artificial lighting, could disturb physiological melatonin production and cause sleep disorders, which was estimated to affect $\sim 20 \%$ of the population in the US. As a result, melatonin is one of the most popular supplements for the treatment of insomnia and jetlag. In addition to entraining the sleep-wake rhythm ${ }^{6}$, the effects of melatonin via activation of MTs regulate other physiological processes, including modulating the cardiovascular system 7 and buffering the immune system ${ }^{8}$. Emerging roles of MTs have also been confirmed in cancer protection $^{9,10}$, bone formation ${ }^{11}$, glucose maintenance ${ }^{12}$, and neurodegenerative disorders ${ }^{9}$. Therefore, designing therapeutic agents targeting MTs has been continuously pursued in the drug discovery field 9 .

In humans, the MT family consists of two highly conserved members, termed $\mathrm{MT}_{1}$ and $\mathrm{MT}_{2}$, and they share $55 \%$ and $70 \%$ sequence similarity for the overall region and the transmembrane part, respectively. Both $\mathrm{MT}_{1}$ and $\mathrm{MT}_{2}$ predominantly signal through $\mathrm{G}_{\mathrm{i} / \mathrm{o}}$ proteins ${ }^{13}$, leading to inhibition of adenylyl cyclase and decreased intracellular concentrations of adenosine 3', $5^{\prime}$-cyclic monophosphate (cAMP). For other G-protein families, the exact coupling profile remains unclear. However, coupling of the $\mathrm{MT}_{1}$ receptor to $\mathrm{G}_{\mathrm{q} / 11}$ was consistently observed ${ }^{14}$. In the brain, $\mathrm{MT}_{1}$ is expressed in the Locus Coeruleus and lateral hypothalamus (REM areas) ${ }^{15,16}$, but $\mathrm{MT}_{2}$ is mainly located in the reticular thalamus (NREM area) $)^{15,16}$. The signaling variation and localization difference probably result in the distinct in vivo functions of $\mathrm{MT}_{1}$ and $\mathrm{MT}_{2}{ }^{17}: \mathrm{MT}_{1}$ is mainly implicated in the regulation of rapid eye movement (REM) phases of the vigilance state in sleep ${ }^{18}$; MT2 selectively increases non-REM (NREM) sleep ${ }^{17-19}$. In addition, single nucleotide polymorphisms (SNPs) revealed that $\mathrm{MT}_{2}$ is exclusively functionally relevant to type- 2 diabetes $(\mathrm{T} 2 \mathrm{D})^{12}$. Given the different physiological roles of $\mathrm{MT}_{1}$ and $\mathrm{MT}_{2}$, obtaining selective ligands is highly desirable. However, most of the drugs on the market or under clinical evaluation, such as ramelteon ${ }^{20}$, tasimelteon $^{21}$, and agomelatine ${ }^{22}$, are nonselective ${ }^{23,24}$. Currently, developing subtype-selective drugs, especially $\mathrm{MT}_{1}$-selective drugs, is very difficult. Moreover, the pharmacophores of the currently available melatonergic agonists are limited to very few types ${ }^{25}$. For example, an indene or naphthalene bioisostere group was repeatedly applied in melatonergic ligands ${ }^{23-25}$. Therefore, delineating the detailed configuration of the ligand-binding pocket of MTs is of great value for effective drug design. In this study, we determined the cryo-EM structures of active melatonin receptors engaged with the heterotrimeric $G_{i}$ protein. These structures reveal distinctive features of the orthosteric pocket in active MTs and provide insights into MT activation and G protein-coupling preference.

\section{Result}

The overall structure of the $\mathrm{MT}_{1}$ and $\mathrm{MT}_{2}$ signaling complex. To obtain stable $\mathrm{MT}_{1}-\mathrm{G}_{\mathrm{i}}$ protein complexes, the nonselective agonists 2-iodomelatonin ${ }^{26}$ and ramelteon ${ }^{20}$ exhibiting high potency and affinity for the melatonin receptor were used. The receptor and G protein were co-expressed in insect cells. The assembled complexes were then purified to homogeneity for single-particle cryo-EM studies. The structures of 2-iodomelatonin- and ramelteon-bound $\mathrm{MT}_{1}-\mathrm{G}_{\mathrm{i}}$ complexes were determined with global resolutions of 3.1 and $3.3 \AA$, respectively (Fig. 1, Supplementary Figs. 1 and 2 and Supplementary Table 1). The relatively high-quality density maps of the two complexes together with the previously solved inactive structure of $\mathrm{MT}_{1}$ enabled us to confidently build atomic models composed of the ligands $\mathrm{MT}_{1}, \mathrm{G}_{\mathrm{i}}$, and $\mathrm{scFv} 16^{27}$. The majority of the side chains of $\mathrm{MT}_{1}$

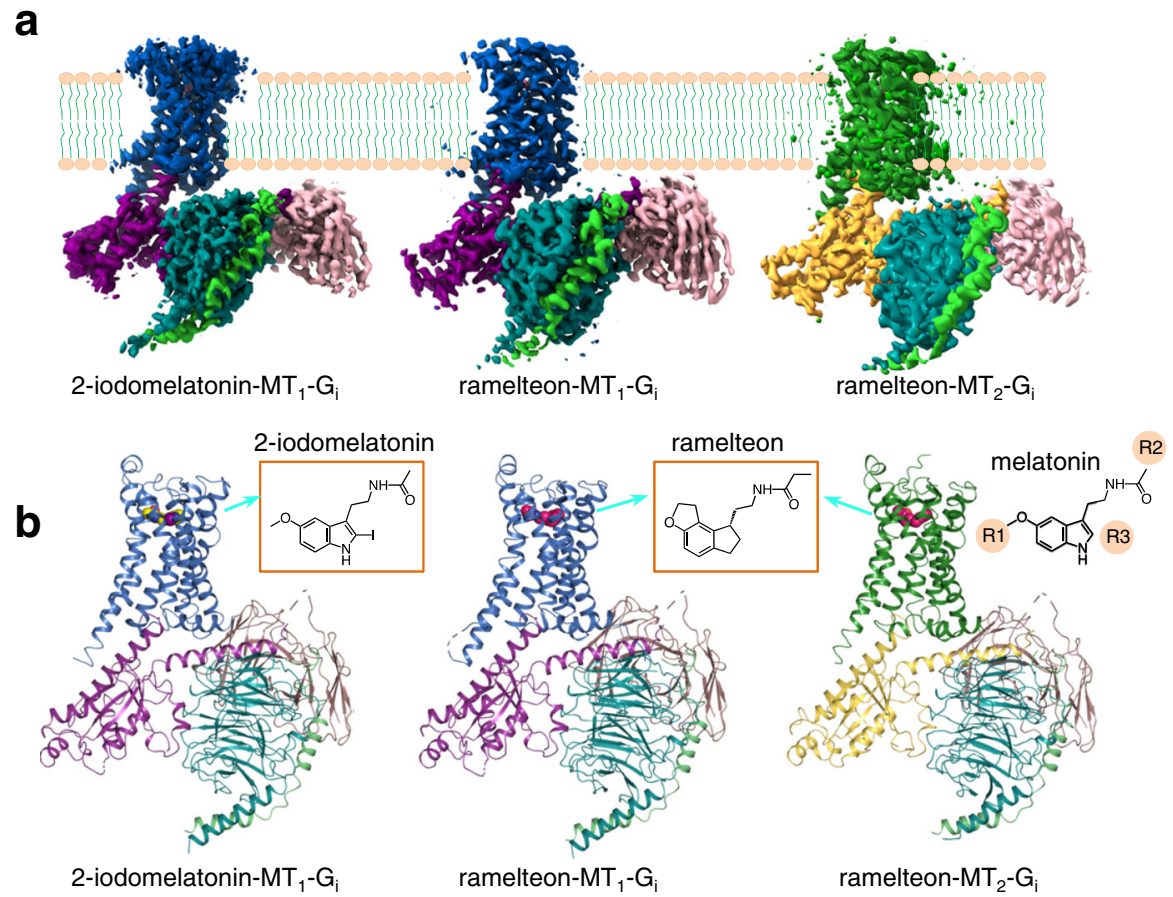

Fig. 1 Overall structures of the $\mathbf{M T}_{\mathbf{1}}-\mathbf{G}_{\mathbf{i}}$ and $\mathbf{M T}_{\mathbf{2}}-\mathbf{G}_{\mathbf{i}}$ signaling complexes. a Cryo-EM density maps of the $M T_{1}-G_{i}$ and $M T_{2}-G_{i}$ complexes. The color code is as follows: $\mathrm{MT}_{1}$, blue; $\mathrm{MT}_{2}$, green; $\mathrm{G}_{\alpha \mathrm{i}}$ in $\mathrm{MT}_{1}$, purple; $\mathrm{G}_{\alpha \mathrm{i}}$ in $\mathrm{MT}_{2}$, yellow; $\mathrm{G}_{\beta}$, teal; $\mathrm{G}_{\gamma}$, light green; scFV16, violet. $\mathbf{b}$ Cryo-EM structures of the $M T_{1}-\mathrm{G}_{i}$ and $M T_{2}-G_{i}$ complexes. Left, 2-iodomelatonin-bound $M T_{1}-G_{i}$; middle, ramelteon-bound $M T_{1}-G_{i}$; right, ramelteon-bound $M T_{2}-G_{i}$. The structures of the respective ligand and the melatonin molecule (right) are shown. 
and $G_{i}$ protein residues are well defined in the structures (Supplementary Figs. 1 and 2). In addition to the protein part, an extra density located between the N-terminal portion of TM1 and TM7 was modeled as a cholesterol molecule.

The same strategy was then applied to prepare the agonistbound $\mathrm{MT}_{2}-\mathrm{G}_{\mathrm{i}}$ complex. Eventually, the reconstituted ramelteonbound $\mathrm{MT}_{2}-\mathrm{G}_{\mathrm{i}}$-scFv16 complex was subjected to cryo-EM data acquisition. After processing 120k particles from 3519 movies, an EM map of only $4.5 \AA$ resolution was acquired. We speculated that improving the stability of the receptor might be helpful for obtaining high-resolution maps. Therefore, the three thermostable mutations, $\mathrm{L} 108^{\mathrm{ECL} 1} \mathrm{~F} / \mathrm{F} 129^{3.41} \mathrm{~W} / \mathrm{C} 140^{3.52} \mathrm{~L}$, based on previous findings ${ }^{28}$, were chosen and introduced into $\mathrm{MT}_{2}$. These three residues were located far away from the ligandbinding pocket and the $\mathrm{G}$ protein-coupling interface ${ }^{28}$; as a result, their mutations minimally interfered with the function of the receptor in terms of ligand recognition and $G$ protein coupling ${ }^{28}$. With this triple mutant complex of ramelteon- $\mathrm{MT}_{2}-\mathrm{G}_{\mathrm{i}}-\mathrm{scFv} 16$, we obtained an EM density map at a global nominal resolution of $3.5 \AA$, which enabled us to model most portions of the receptor, the ramelteon molecule, the $\mathrm{G}_{i}$ protein, and the scFv16 (Fig. 1, Supplementary Fig. 3 and Supplementary Table 1).

The determined structures reveal that the overall assembly of $\mathrm{MT}_{1}-\mathrm{G}_{\mathrm{i}}$ and $\mathrm{MT}_{2}-\mathrm{G}_{\mathrm{i}}$ is similar to that of the most active GPCR-G-protein complexes (Fig. 1b). Both the ligands of 2-iodomelatonin and ramelteon used for complex reconstitution are bound at the orthosteric pockets of $\mathrm{MT}_{1}$ and $\mathrm{MT}_{2}$ (Fig. 1b). The 2-iodomelatonin-bound $\mathrm{MT}_{1}-\mathrm{G}_{\mathrm{i}}$ complex shares a nearly identical overall structure with that of ramelteon-bound $M_{1}-G_{i}$, with root-mean-square deviation (RMSD) values of $1 \AA$ for the $\mathrm{C} \alpha$ atoms of the whole complexes and $0.8 \AA$ for the $\mathrm{C} \alpha$ atoms of $\mathrm{MT}_{1}$ alone. The ramelteon-bound $\mathrm{MT}_{2}-\mathrm{G}_{\mathrm{i}}$ complex adopts a conformation similar to that of $\mathrm{MT}_{1}-\mathrm{G}_{\mathrm{i}}$, with an RMSD of $1.4 \AA$ for the $\mathrm{C} \alpha$ atoms of the receptor part, reminiscent of the structural similarity of the two receptors in their inactive states. However, noticeable structural differences are also observed on the extracellular side and in the region involved in G-protein engagement, as discussed below.

The orthosteric site and determinants of the ligand selectivity. In both the $\mathrm{MT}_{1}$ and $\mathrm{MT}_{2}$ structures, the ligand of 2-iodomelatonin or ramelteon binds at the orthosteric pocket constituted by TM3, TM5, TM6, TM7, and ECL2 (Fig. 2a, c). The binding pose of the ramelteon in active $\mathrm{MT}_{1}$ or $\mathrm{MT}_{2}$ is superimposable with those in inactive structures (Supplementary Fig. 4). However, the binding pose of the 2-iodomelatonin in the active structure is slightly different from that in the inactive structure, especially in the region of the alkylamide tail, which moves closer to the toggle switch residue $\mathrm{W}^{6.48}$ in active $\mathrm{MT}_{1}$ (Supplementary Fig. 4). ECL2 sits on the top of the pocket and completely blocks ligand access from the extracellular side in both structures (Fig. 2b, d). The only entrance to the orthostericbinding site in the active state is the previously identified lateral channel between TM4 and TM5 (Fig. 2b, d). Comparison of the orthosteric pocket from active and inactive structures revealed remarkable differences: the pocket in the active structures is more constricted in the central part, but it extends to connect with a wide "longitudinal channel" formed by TM3, TM4, and TM5 (Fig. 2b, d). Inspection of the residues around the pockets reveals that while those surrounding the iodine group and alkylamide tail (named $\mathrm{R}^{3}$ position in melatonin, Fig. 1) align well, several residues lining the solvent channel present very different conformations (Fig. 2e, f), which results in the varied configuration of the active pocket. Specifically, the aromatic residue Y1875.38 in $\mathrm{MT}_{1}$ rotates from the solvent-facing conformation in the inactive structure toward TM4 and forms a hydrogen bond with N1624.60 in the active structure (Fig. 2e). This hydrogen bond further reduces the diameter of the ligand entrance and could restrict the release of the bound agonist, as the Y187 $7^{5.38} \mathrm{~A}$ mutation led to a fast ligand dissociation rate 27,28 . In addition, the $\mathrm{N} 162^{4.60} \mathrm{~A}$ mutation disrupted the function of $\mathrm{MT}_{1}$, again highlighting the functional importance of this hydrogen pair in $\mathrm{MT}_{1}$ activation ${ }^{27,28}$ (Supplementary Fig. 5). In $\mathrm{MT}_{2}$, the corresponding pair N1754.60 and Y200 5.38 also experienced conformational changes during transmission from the inactive to the active state (Fig. 2f). However, they take an opposite manner, and the hydrogen bond formed in the inactive structure disappears in the active structure (Fig. 2f). The absence of this hydrogen bond indicates that $\mathrm{MT}_{2}$ does not need an $\mathrm{MT}_{1}$-like entrance-restricting hydrogen bond for activation, correlating well with the previous finding that the N175.60 A mutation showed no functional impairment ${ }^{27,28}$ (Supplementary Fig. 5). Notably, to facilitate the conformational changes of this $\mathrm{N}^{4.60}-\mathrm{Y}^{5.38}$ pair, a conserved proline $\left(\mathrm{P}^{4.59}\right)$ is located close to $\mathrm{N}^{4.60}$ in $\mathrm{MT}_{1}$ and $\mathrm{MT}_{2}$, and mutation of $\mathrm{P}^{4.59}$ disrupts the ligand-binding activity of $\mathrm{MT}_{2}{ }^{29}$.

In addition to the conformational changes in the $\mathrm{N}^{4.60}-\mathrm{Y}^{5.38}$ pair, residue $\mathrm{H}^{5.46}$ ( $\mathrm{H} 195^{5.46}$ in $\mathrm{MT}_{1}$ and $\mathrm{H}_{208^{5.46}}$ in $\mathrm{MT}_{2}$ ) (Fig. 2e, f), which is positioned two helical turns below $\mathrm{Y}^{5.38}$, displays the most striking difference in the pockets from the inactive and active structures (Fig. 2e, f). In the inactive structures, $\mathrm{H}^{5.46}$ packs against TM4 and stays far away from the bound ligand (Fig. 2e, f). However, in the active structures, it undergoes a $2.4 \AA$ inward displacement and adopts a flipped rotamer of the side chain, creating van der Waals interactions with the alkylamide tail of the bound ligand and the toggle switch residue $\mathrm{W}^{6.48}$ (W251 ${ }^{6.48}$ in $\mathrm{MT}_{1}$ and W264 ${ }^{6.48}$ in $\mathrm{MT}_{2}$ ) (Fig. 2e, f). This rearranged conformation of $\mathrm{H}^{5.46}$ explains the previous observation that the $\mathrm{H} 208^{5.46} \mathrm{~A}$ mutation affected $\mathrm{MT}_{2}$ function ${ }^{28,30}$. Interestingly, although $\mathrm{H}^{5.46}$ undergoes similar conformational changes in $\mathrm{MT}_{1}$ and $\mathrm{MT}_{2}$, its functional importance seems to be different in the two receptors, as the mutation of $\mathrm{H} 208^{5.46}\left(\mathrm{MT}_{2}\right)$ only moderately impaired the function of $\mathrm{MT}_{2}$, but the $\mathrm{H} 195^{5.46} \mathrm{~A}\left(\mathrm{MT}_{1}\right)$ mutation caused a deleterious effect, as reflected by the low expression level of the mutant ${ }^{27,28}$. Owing to the movement of $\mathrm{H}^{5.46}$, additional space adjacent to the methoxy group of 2-iodomelatonin (named $\mathrm{R}^{1}$ position in melatonin) is produced, resulting in the formation of the abovementioned "longitudinal channel" (Fig. 2b, d). We then docked two representative ligands that possess moderate $\mathrm{MT}_{1}$ selectivity, 5-hydroxyethoxy-Nacetyltryptamine (5-HEAT) ${ }^{31}$ and CTL 01-05-B-A0527, to both receptors (Supplementary Fig. 6). Compared to melatonin, both 5-HEAT and CTL 01-05-B-A05 have substituents at the R1 position. In $\mathrm{MT}_{1}, 5$-HEAT occupied a position superimposable with that of the bound 2-iodomelatonin by forming hydrogen bonds with $\mathrm{N} 162^{4.60}$ and $\mathrm{Y}^{187^{5.38}}$ (Fig. 2g). Thus, the molecular structure of 5-HEAT is probably compatible with the pose of the active pocket required to activate $\mathrm{MT}_{1}$, resulting in 5-HEAT being an agonist of $\mathrm{MT}_{1}$. In contrast, as an antagonist of $\mathrm{MT}_{2}, 5$-HEAT did not take a plausible docking position in the observed active pocket of $\mathrm{MT}_{2}$, probably due to the varied conformations of $\mathrm{N} 175^{4.60}$ and $\mathrm{Y} 200^{5.38}$ 5-HEAT probably utilizes an induced-fit model for binding $\mathrm{MT}_{2}$, and the resultant configuration of the $\mathrm{MT}_{2}$ pocket probably loses the ability to induce intracellular structural rearrangement. CTL 01-05B-A05 adopts an extended conformation in $\mathrm{MT}_{1}$ with the second naphthalene group packing against F194 5.45 (Fig. 2h). However, CTL 01-05-B-A05 binding to $\mathrm{MT}_{2}$ was suboptimal, as the stacking interaction was disrupted by the precluding side chain of $1207^{5.45}$ at the corresponding position (Fig. 2i). Notably, based on our results, it is worth further optimizing the bitopic ligand to obtain more selective $\mathrm{MT}_{1}$ agonists. For example, introducing novel substituents into the second unit for optimal fitting with the "longitudinal channel" will be a promising strategy. 

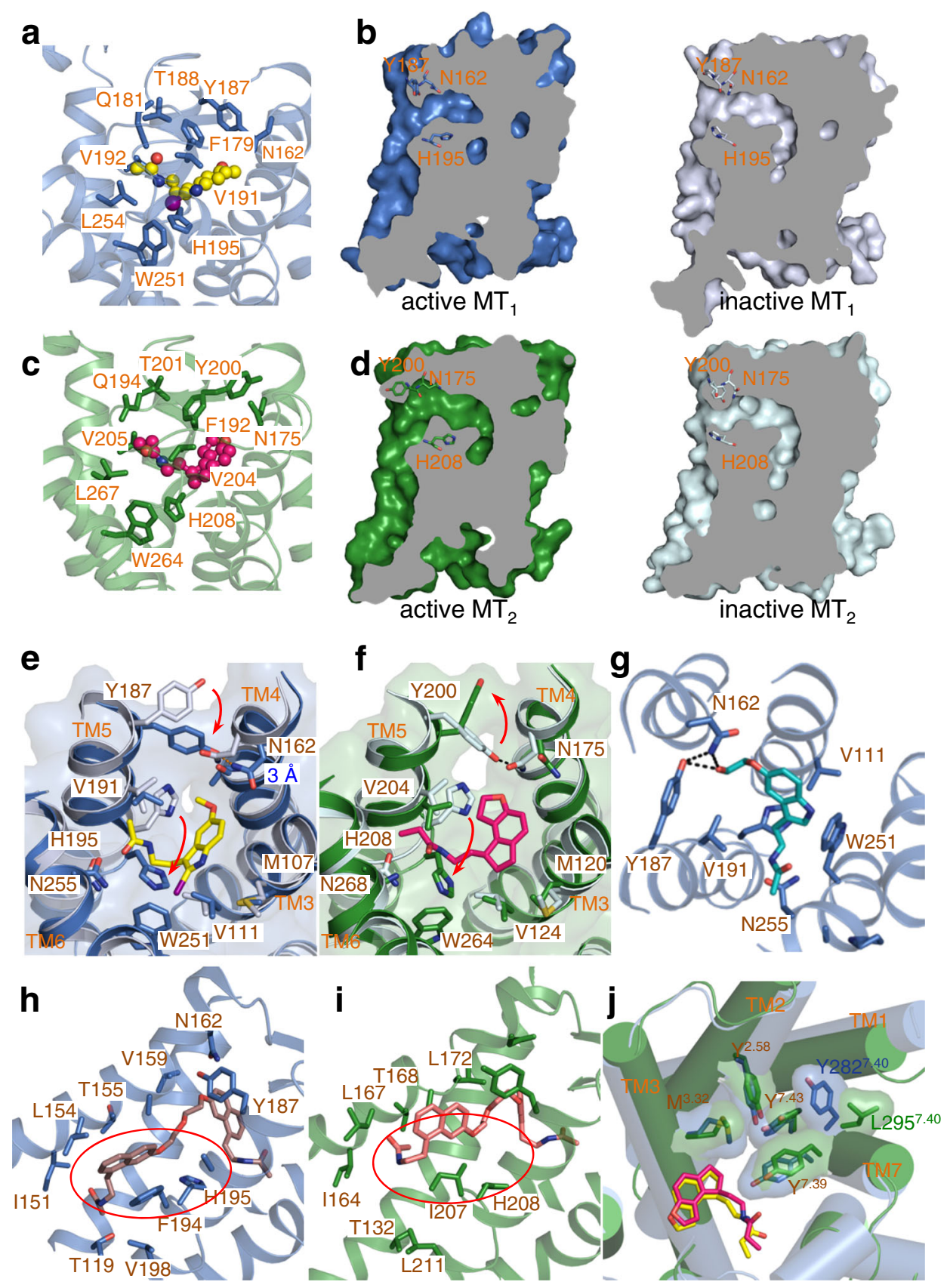

Fig. 2 Ligand-binding pocket and selectivity determinants. a The ligand-binding pocket bound with the 2-iodomelatonin (yellow) in $\mathrm{MT}_{1}$ (blue). b Slab view showing the ligand access channel of $\mathrm{MT}_{1}$ in active (left) and inactive structures (right, light blue, PDB ID: 6ME4). c The ligand-binding pocket bound with the ramelteon (pink) in $\mathrm{MT}_{2}$ (green). d Slab view showing the ligand access channel of $\mathrm{MT}_{2}$ in active (left) and inactive structures (right, light cyan, PDB ID: 6ME9). e Comparison of the residues from the active (blue) and inactive (light blue) ligand-binding pockets of $M_{1}$. Red arrows indicate remarkable conformational changes. The distance between the two atoms forming the N162/Y187 hydrogen bond is $3 \AA$. f Comparison of the residues from the active (green) and inactive (light cyan) ligand-binding pockets of $\mathrm{MT}_{2}$. Red arrows indicate remarkable conformational changes. $\mathbf{g}$ 5-HEAT (cyan) docked in the active $\mathrm{MT}_{1}$. Key interacting residues from the pocket are shown as sticks. $\mathbf{h}$ CTL 01-05-B-A05 (salmon) docked in the active $\mathrm{MT}_{1}$. The red circle indicates the hydrophobic packing between F1945.45 and the naphthalene group. i CTL 01-05-B-A05 (salmon) docked in the active MT2. The red circle highlights the incompatible packing between $1207^{5.45}$ and the naphthalene group. $\mathbf{j}$ Comparison of the subpockets from active $\mathrm{MT}_{1}$ (blue) and $\mathrm{MT}_{2}$ (green) bound with ramelteon (red in $\mathrm{MT}_{1}$, yellow in $\mathrm{MT}_{2}$ ). Key different residues are shown as sticks.

Although the pockets from inactive $\mathrm{MT}_{1}$ and $\mathrm{MT}_{2}$ showed only subtle conformational differences in the region around the $\mathrm{R}^{3}$ group of the ligand (termed subpocket), they became more discriminative in the active structures. $\mathrm{MT}_{1}$ has a tyrosine at the

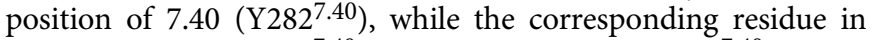
$\mathrm{MT}_{2}$ is a leucine (L295 ${ }^{7.40}$ ) (Fig. 2j). Packing of Y282 $2^{7.40}$ against TM1 pushes the two adjacent residues Y281 ${ }^{7.39}$ and Y285 closer to the core of the pocket than the equivalent residues $\mathrm{Y}_{294^{7.39}}$ and $\mathrm{Y}_{298^{7.43}}$ in $\mathrm{MT}_{2}$ (Fig. 2j). As a result, $\mathrm{MT}_{2}$ has a larger subpocket, allowing the accommodation of ligands with bulky $\mathrm{R}^{3}$ substituents, consistent with the molecular structures of most $\mathrm{MT}_{2}$ selective agonists ${ }^{23,30}$. In summary, the structural and functional data revealed that although the ligand-binding pockets in $\mathrm{MT}_{1}$ and $\mathrm{MT}_{2}$ share similarities, they also present distinct 


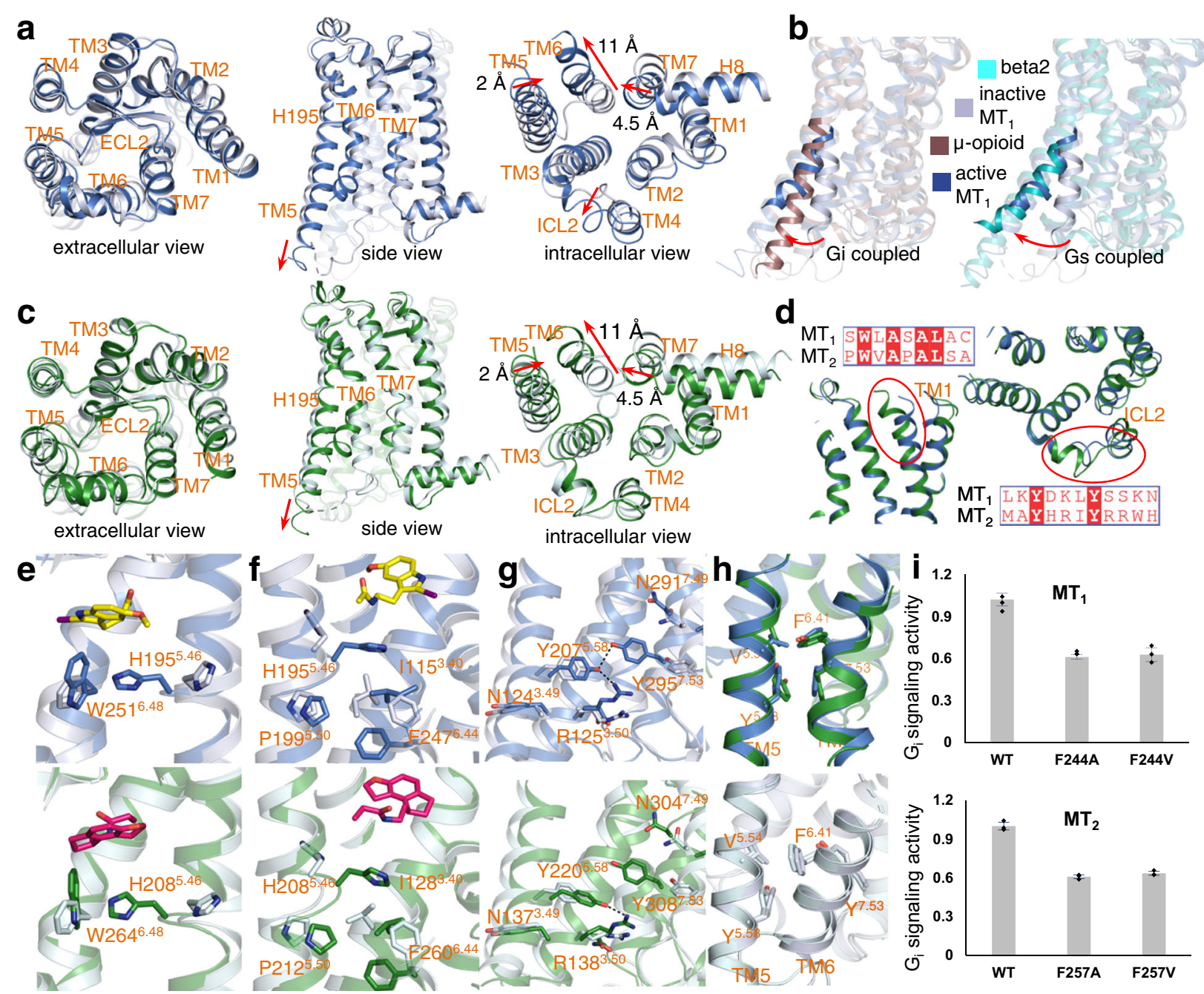

Fig. $3 \mathbf{M T}_{\mathbf{1}}$ and $\mathbf{M T}_{\mathbf{2}}$ activation. a Structural comparison of the active (blue) and inactive (light blue) $\mathrm{MT}_{1}$. Three views are presented. $\mathbf{b}$ Comparison of the conformation of $\mathrm{TM} 6$ from $\mathrm{MT}_{1}$ with that from the $\mathrm{G}_{\mathrm{i}}$-coupled receptor $\mu$-opioid (left, PDB ID: 6DDE) receptor and $\mathrm{G}_{\mathrm{s}}$-coupled receptor beta2 (right, PDB ID: 3SN6). c Structural comparison of active (green) and inactive (light green) $\mathrm{MT}_{2}$. Three views are presented. $\mathbf{d}$ Comparison of TM1 (left) and ICL2 (right) from $\mathrm{MT}_{1}$ and $\mathrm{MT}_{2}$. e- $\mathbf{g}$ Conformational changes of the key residues and motifs during receptor activation in $\mathrm{MT}_{1}$ (above) and $\mathrm{MT}_{2}$ (below). $\mathbf{h} \mathrm{The}$ conformations of $\mathrm{F}^{6.41}$ in active (above) and inactive (below) $\mathrm{MT}_{1}$ and $\mathrm{MT}_{2}$ structures. $\mathbf{i}$ The Gi signaling ability of the $\mathrm{F}^{6.41}$ mutant of $\mathrm{MT}_{1}$ and $\mathrm{MT}_{2}$. Data were normalized to that of the wild-type receptor and presented as the means \pm standard error of three replicates.

features. The unique configuration of the $\mathrm{N}^{4.60}-\mathrm{Y}^{5.38}-\mathrm{H}^{5.46}$ motif and the "longitudinal channel" in $\mathrm{MT}_{1}$ and the larger subpocket in $\mathrm{MT}_{2}$ could be targeted to design MT subtypeselective drugs.

The active conformation of $\mathbf{M T}_{\mathbf{1}}$ and $\mathbf{M T}_{2} . \mathrm{MT}_{1}$ from the $\mathrm{G}_{\mathrm{i}^{-}}$ coupled structures adopts an active conformation with the characteristic of TM6 outward displacement, similar to the other active GPCRs. Comparison of the active and inactive structures revealed that $\mathrm{MT}_{1}$ maintains a similar conformation on the extracellular side, probably because both of them were stabilized by the agonist (Fig. 3a). In contrast, extensive structural rearrangements occur at the intracellular part (Fig. 3a). Among them, the $11 \AA$ outward displacement of TM6 is most striking (Fig. 3a). In general, the outward displacement angle of TM6 is smaller in Gi/o-coupled GPCRs than in Gs-coupled GPCRs. However, $\mathrm{MT}_{1}$ TM6 has a relatively large displacement, reaching the extent observed in $\mathrm{G}_{\mathrm{s}}{ }^{-}$ coupled GPCRs ${ }^{32}$ (Fig. $3 \mathrm{~b}$ and Supplementary Fig. 7). This unusual movement of TM6 is coordinated by the unique structural motifs in MTs, as discussed below. Accompanying TM6 movement, TM7 also undergoes conformational changes, and it takes $4.5 \AA$ movement toward TM6 (Fig. 3a). Induced by the reorientation of $\mathrm{H} 195^{5.46}$ TM5 also shifts $2 \AA$ closer to TM6 (Fig. 3a). Moreover, its cytoplasmic end, which mediates interactions with the Ras-like domain of $\mathrm{G}_{\alpha \mathrm{s}}$, is extended by two additional helical turns in the active structure (Fig. 3a). Last, residue $\mathrm{C} 130^{3.55}$ bends the TM3 helix and reshapes the trajectory of ICL2 (Fig. 3a and Supplementary Fig. 8). This repositioning of TM3 and ICL2 is necessary for $G_{i}$ accommodation; otherwise, they would make a severe steric clash with the $\alpha \mathrm{N}$ of $\mathrm{G}_{\mathrm{i}}$ (Supplementary Fig. 8). Consistently, the $\mathrm{MT}_{1} \mathrm{C} 130^{3.55}$ mutation led to a decreased G-protein activation ability ${ }^{33}$.

As expected, $\mathrm{MT}_{2}$ also undergoes structural rearrangements in the regions of TM5, TM6, and TM7, resulting in an active conformation almost identical to that of $\mathrm{MT}_{1}$ (Fig. 3c), consistent with their sequence homology and the structural resemblance between the inactive states. Conformational differences between active $\mathrm{MT}_{1}$ and $\mathrm{MT}_{2}$ were only observed in the extracellular end of TM1 and ICL2, where minimal sequence conservation exists (Fig. 3d). As mentioned above, the bulky $\mathrm{Y}_{282^{7.40}}$ in $\mathrm{MT}_{1}$, which is linked to the slight differences between the ligand-binding pockets, pushes TM1 more outward from the TM bundle (Fig. 3d). ICL2 in $\mathrm{MT}_{2}$ adopts a different trajectory than that in $\mathrm{MT}_{1}$ (Fig. 3d). The varied ICL2 in terms of sequence composition 
and spatial localization probably confers the slightly different $G$ protein-coupling profiles of $\mathrm{MT}_{1}$ and $\mathrm{MT}_{2}$, as discussed below.

Comparison of the conserved motifs in $\mathrm{MT}_{1}$ and $\mathrm{MT}_{2}$ with those in other class A GPCRs reveals that they possess common as well as unique features. The toggle switch $\mathrm{W}^{6.48}$ (W251 ${ }^{6.48}$ in $\mathrm{MT}_{1}$ and $\mathrm{W}_{264^{6.48}}$ in $\mathrm{MT}_{2}$ ) makes direct contact with the alkylamide tail of the ligand (Fig. 3e), accounting for the linkage between ligand binding and receptor activation. Based on the established activation mechanism of GPCRs, the toggle switch residue often undergoes conformational changes upon agonist binding. However, how $\mathrm{MT}_{1}$ and $\mathrm{MT}_{2} \mathrm{~W}^{6.48}$ experience conformational changes remain unknown, as the state of $\mathrm{W}^{6.48}$ from an inactive structure is lacking. $\mathrm{W}^{6.48}$ was mutated to Phe in the previous inactive structures for stability improvement. The triadmotif $\mathrm{P}^{5.50}-\mathrm{I}^{3.40}-\mathrm{F}^{6.44}$, which is located close to the toggle switch, also experiences classical rearrangement (Fig. 3f). Interestingly, the repositioned $\mathrm{H}_{195^{5.46}}\left(\mathrm{H} 208^{5.46}\right.$ in $\mathrm{MT}_{2}$ ) in active $\mathrm{MT}_{1}$ sits right between the ligand and $\mathrm{I}^{3.40}$ from the triadmotif and simultaneously forms interactions with the ligand and $\mathrm{I}^{3.40}$ (Fig. 3e, f). Therefore, H195 $5^{5.46}$ might cooperate with $\mathrm{W}^{6.48}$ to link ligand binding with receptor activation: agonistic ligand binding to the orthosteric site induces conformational changes in $\mathrm{H} 195^{5.46}$ and $\mathrm{W}^{6.48}$ by forming direct interactions; $\mathrm{H} 195^{5.46}$ and $\mathrm{W}^{6.48}$ then propagate the signals to the $\mathrm{P}^{5.50}-\mathrm{I}^{3.40}-\mathrm{F}^{6.44}$ triadmotif located right below; and the rearranged triadmotif finally drives the movement of TM5 and TM6, leading to receptor activation. On the intracellular side, the typical $\mathrm{N}^{7.49} \mathrm{P}^{7.50} \mathrm{xxY}^{7.53}$ motif in TM7 is replaced with $\mathrm{N}^{7.49} \mathrm{~A}^{7.50} \mathrm{xxY}^{7.53}$ in $\mathrm{MT}_{1}$ and $\mathrm{MT}_{2}$. This unusual motif is functionally essential, as the converted $\mathrm{N}^{7.49} \mathrm{P}^{7.50} \mathrm{xxY}^{7.53}$ motif led to a loss of function in $\mathrm{MT}_{2}{ }^{29}$. Similarly, the canonical $\mathrm{D}^{3.49} \mathrm{R}^{3.50} \mathrm{Y}^{3.51}$ motif was changed to $\mathrm{N}^{3.49} \mathrm{R}^{3.50} \mathrm{Y}^{3.51}$ in $\mathrm{MT}_{1}$ and $\mathrm{MT}_{2}$. $\mathrm{Y}^{5.58}$ in TM5 forms hydrogen bonds with both $\mathrm{R}^{3.49}$ and $\mathrm{Y}^{7.53}$, acting to tether the cytoplasmic ends of TM3, TM5, and TM7 (Fig. 3g). Notably, the commonly observed small hydrophobic residue $\mathrm{V}^{6.41}$ in most class A GPCRs is replaced by $\mathrm{F}^{6.41}$ in $\mathrm{MT}_{1}$ and $\mathrm{MT}_{2}$. In the inactive structures, $\mathrm{F}^{6.41}$ points outside and packs against $\mathrm{V}^{5.54}$. However, in the active structures, it flips close to $\mathrm{Y}^{7.53}$ and stacks with $\mathrm{Y}^{5.58}$ (Fig. 3h). This special hydrophobic core induces the particularly wide opening of TM6. Mutation of $\mathrm{F}^{6.41}$ into valine or alanine crippled the signaling activity of $\mathrm{MT}_{1}$ and $\mathrm{MT}_{2}$, demonstrating that a large cytoplasmic cavity is required for $\mathrm{G}_{\mathrm{i}}$ engagement in $\mathrm{MT}_{1}$ and $\mathrm{MT}_{2}$ (Fig. 3i). In summary, through structural rearrangements mediated by classical and unique microswitches, $\mathrm{MT}_{1}$ and $\mathrm{MT}_{2}$ adopt a similar active conformation with a wide opening in the cytoplasmic core.

Interactions between $\mathbf{M T}_{\mathbf{1}}, \mathbf{M T}_{\mathbf{2}}$, and $\mathbf{G}_{\mathbf{i}}$. The interactions between $\mathrm{MT}_{1}, \mathrm{MT}_{2}$, and $\mathrm{G}_{\mathrm{i}}$ are mainly mediated by the a 5 helix of the $\mathrm{G}_{\mathrm{ai}}$ subunit, and the receptor cores comprise TM3 and TM5-7 from $\mathrm{MT}_{1}$ and $\mathrm{MT}_{2}$ (Fig. 4a). Although ICL2 forms hydrophobic or polar interactions with the $G$ protein in most GPCRs, it mediates minimal contact with $\alpha 5$ and $\alpha \mathrm{N}$ in $\mathrm{G}_{\mathrm{i}}$ bound to $\mathrm{MT}_{1}$ and $\mathrm{MT}_{2}$ (Fig. $4 \mathrm{~b}$ ). As a result, the $\mathrm{G}_{\mathrm{i}}$ interfaces in $\mathrm{MT}_{1}$ and $\mathrm{MT}_{2}$ are almost indistinguishable (Fig. 4a). Interestingly, even though $\mathrm{MT}_{1}$ and $\mathrm{MT}_{2}$ employ a nearly identical set of residues for accommodating $G_{i}$, the bound $G_{i}$ still displays slightly different conformations (Fig. 4b). $a 5$ and $\alpha \mathrm{N}$ in $\mathrm{MT}_{2}-\mathrm{G}_{\mathrm{i}}$ have outward displacements of 1 and $2 \AA$, respectively, compared to $\mathrm{MT}_{1}-\mathrm{G}_{\mathrm{i}}$ (Fig. $4 \mathrm{~b}$ ). This conformational difference may be attributed to ICL2. The varied ICL2 in $\mathrm{MT}_{1}$ and $\mathrm{MT}_{2}$ might pose different impacts during $G_{i}$ engagement, which results in the observed $G_{i}$ conformations. Another possibility is that these two structures represent different conformational states during $G_{i}$ binding to $\mathrm{MT}_{1}$ and $\mathrm{MT}_{2}$. Although the $\mathrm{MT}_{1}-\mathrm{G}_{\mathrm{i}}$ and $\mathrm{MT}_{2}-\mathrm{G}_{\mathrm{i}}$ complexes adopt a commonly observed overall assembly mode, they display distinct features as well. When aligned on the receptors, the $G_{i}$ bound to $M T_{1}$ and $M T_{2}$ show a relative orientation completely different from those presented by the $G_{i}$ in complex with the $\mu$-opioid ${ }^{34}$, dopamine $D 2^{35}, C B 1$ cannabinoid $^{36}$, and NTSR1 neurotensin receptors ${ }^{37}$ (Fig. 4c). The a5 helix in $\mathrm{MT}_{1}-\mathrm{G}_{\mathrm{i}}$ and $\mathrm{MT}_{2}-\mathrm{G}_{\mathrm{i}}$ undergoes significant rotational and translational movement away from TM3 and forms tight packing interactions with TM5 in an antiparallel manner (Fig. 4c). In contrast, owing to the large outward displacement of TM6, much fewer contacts are formed between TM6 and $G_{\alpha i}$ in the $\mathrm{MT}_{1}-\mathrm{G}_{\mathrm{i}}$ and $\mathrm{MT}_{2}-\mathrm{G}_{\mathrm{i}}$ complexes (Fig. 4c).

Hydrophobic contacts dominate the part formed between the C-terminus of $a 5$ helix and the receptor core, exemplified by the I344 ${ }^{\text {G.H5.16 }}$, L348 ${ }^{\text {G.H5.20 }}$, L353 G.H5.25, and C $351^{\text {G.H5.23 interacting }}$ with the residues from TM3, TM5, and TM6 (Fig. 4d, e). Remarkably, the involved $\mathrm{Y}^{3.53}$ in $\mathrm{MT}_{1}$ and $\mathrm{MT}_{2}$ frequently appears as alanine in most class A GPCRs. In $\mathrm{MT}_{1}-\mathrm{G}_{\mathrm{i}}$ and $\mathrm{MT}_{2^{-}}$ $\mathrm{G}_{\mathrm{i}}$, the bulky side chain of $\mathrm{Y}^{3.53}$ probably contributes to establishing the special position of $\mathrm{G}_{\mathrm{i}}$ by restricting the a5 helix from moving away from TM5 (Fig. 4d, e). Indeed, mutation of $\mathrm{Y}^{3.53}$ of $\mathrm{MT}_{2}$ caused impaired $\mathrm{G}_{\mathrm{i}}$ signaling ability ${ }^{38}$. In $\mathrm{MT}_{1}$, $\mathrm{V} 221^{5.72}$ mediates another hydrophobic contact by burying its side chain into a hydrophobic pocket formed by Y320 G.S6.01, F334 G.H5.06, and A337G.H5.09 (Fig. 4f). Polar interactions are also observed in the MT- $\mathrm{G}_{\mathrm{i}}$ interface and are mainly contributed by the three basic residues located in the cytoplasmic end of TM5: $\mathrm{R}^{5.69}$ forms a salt bridge with E318 $8^{\mathrm{G} . h 4} 4 \mathrm{~s} 6.12$ from $\mathrm{G}_{a \mathrm{i}} ; \mathrm{R}^{5.71}\left(\mathrm{~K}^{5.71}\right.$ in $\mathrm{MT}_{2}$ ) and $\mathrm{K}^{5.73}$ forms a hydrogen bond with T340 G.H5.12 and the backbone carbonyl of I319G.S6.01, respectively (Fig. 4f). Due to the a5 movement away from TM3, most of the previously observed interactions between ICL2 and $\alpha \mathrm{N}$ disappear in $\mathrm{MT}_{1}-\mathrm{G}_{\mathrm{i}}$ and $\mathrm{MT}_{2}-\mathrm{G}_{\mathrm{i}}$ complexes. For example, the well-known interaction mediated by the side chain of residue 34.51 from ICL2 and the hydrophobic cavity formed by the $\alpha 5, \alpha \mathrm{N}$, and $\beta 2-\beta 3$ loop of $\mathrm{G}_{\alpha \mathrm{i}}$ is not observed in the $\mathrm{MT}_{1}-\mathrm{G}_{\mathrm{i}}$ and $\mathrm{MT}_{2}-\mathrm{G}_{\mathrm{i}}$ complexes.

Although $\mathrm{MT}_{1}$ and $\mathrm{MT}_{2}$ share almost identical residues in the receptor core, they still possess varied $G$ protein-coupling abilities. $M_{2}$ exclusively couples to $G_{i / o}$, but $M T_{1}$ could also couple to $G_{q / 11}$. Therefore, $\mathrm{MT}_{1}$ should possess a special region in addition to the observed $G_{i}$ interface to support $G_{\mathrm{q} / 11}$ engagement. As mentioned above, ICL2, which is involved in the G-protein association in most GPCR-G-protein complexes, indeed displays obvious sequence and conformational differences in $\mathrm{MT}_{1}$ and $\mathrm{MT}_{2}$ (Fig. 4a). Thus, ICL2 in $\mathrm{MT}_{1}$ probably participates in the constitution of a unique interface, at which $\mathrm{G}_{\mathrm{q} / 11}$ binds and produces a resultant conformation different from that of the observed $G_{i}$. In fact, this phenomenon has been previously observed for the two closely related receptors $\mathrm{M} 1$ and $\mathrm{M} 2$ muscarinic acetylcholine receptors: $G_{11}$ and $G_{i}$ were bound at different regions in the receptors, and their conformations were also different ${ }^{39}$. Altogether, $\mathrm{MT}_{1}$ and $\mathrm{MT}_{2}$ share a unique $G_{i}$ interface featuring the antiparallel packing of TM5 against the $a 5$ of $G_{i}$, and the varied ICL2 probably confers the additional subtype $\mathrm{G}$ protein-coupling ability of $\mathrm{MT}_{1}$.

Disease-related mutations in $\mathbf{M T}_{2}$ receptor. $\mathrm{MT}_{2}$ loss-offunction has been linked to type- 2 diabetes (T2D) ${ }^{12,38}$. Of the mutants associated with T2D, nearly half impair $G_{i}$ signaling ability. When we mapped these affected sites onto the $M T_{2}-G_{i}$ structure, we observed clustering of residues around the $G_{i}$ interface (Supplementary Fig. 9). Based on their positions, these mutations can be classified into three categories. The first category mutations are in the GPCR key functional motif, such as $\mathrm{R} 138^{3.50} \mathrm{H} / \mathrm{L} / \mathrm{C}$ from the DRY motif and $\mathrm{Y} 308^{7.53} \mathrm{~S}$ of the NAxxY motif. The second category mutations are positioned in the $G_{i}$ 

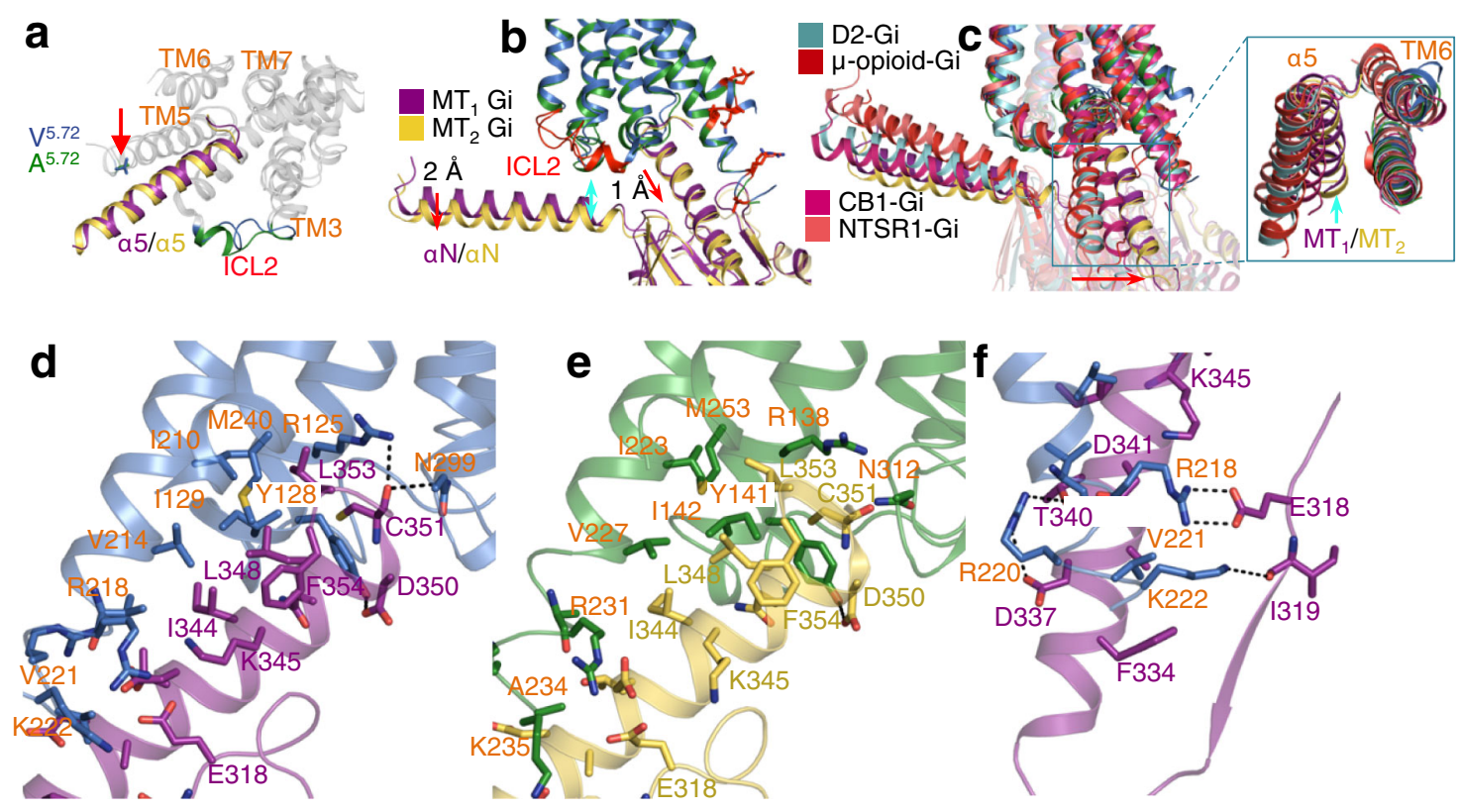

Fig. 4 The $\mathbf{G}_{\mathbf{i}}$ conformations and interfaces in $\mathbf{M} \mathbf{T}_{\mathbf{1}}-\mathbf{G}_{\mathbf{i}}$ and $\mathbf{M} \mathbf{T}_{\mathbf{2}}-\mathbf{G}_{\mathbf{i}}$ complexes. a Comparison of the receptor core (gray) engaging the $\alpha 5$ helix in $M T_{1}-G_{i}$ (purple) and $\mathrm{MT}_{2}-\mathrm{G}_{\mathrm{i}}$ (yellow) complexes. The indicated (red arrow) residue 5.72 is the only different residue $\left(\mathrm{V}^{5.72}\right.$ in $\mathrm{MT}_{1}$ and $\mathrm{A}^{5.72}$ in $\left.\mathrm{MT}_{2}\right)$. b The conformations of the $\mathrm{G}_{i}$ bound to $M T_{1}$ and $M T_{2}$. Displacements of $\alpha \mathrm{N}$ and $\alpha 5$ are highlighted with red arrows. $\alpha \mathrm{N}$ is located far from ICL2, indicated by the cyan arrow. $\mathbf{c}$ The orientations of the $\alpha 5$ helices in $\mathrm{MT}_{1}, \mathrm{MT}_{2}$, and other $\mathrm{G}_{i}$-coupled receptors. $\mathbf{d}$, e $\alpha 5$ helix-mediated interactions in $M T_{1}-\mathrm{G}_{i}(\mathbf{d})$ and $M T_{2}-\mathrm{G}_{i}$ (e) complexes. $\mathbf{f}$ The polar interactions in the $\mathrm{MT}_{1}-\mathrm{G}_{\mathrm{i}}$ interface. Hydrogen bonds are highlighted with dashes.

interface, such as $\mathrm{Y} 141^{3.53} \mathrm{~F}$ and $\mathrm{A} 234^{5.72} \mathrm{~T}$. The third category of mutations is located away from the above-identified functional region. They seem to impair $\mathrm{G}_{\mathrm{i}}$ binding by influencing the conformation of the cytoplasmic core. For example, R222 5.60 , which sits at the cytoplasmic edge of TM5, might contact the phosphate group from the membrane and contribute to shaping the conformation of TM5. Its mutation to histidine probably disrupts this interaction and leads to a varied configuration of TM5 without the $\mathrm{G}_{\mathrm{i}}$ coupling ability.

\section{Discussion}

Melatonin receptors have always been regarded as drug targets for developing therapeutics to treat insomnia, circadian rhythm and mood disorders, and cancer. Efforts to identify novel ligands with exceptional properties have been constantly made in the past four decades. However, only a limited number of chemotypes have been discovered for melatonergic ligands. The reason partially lies in the lack of structures providing information on the orthosteric ligand pocket. Indeed, immediately following the recent structural determination of $\mathrm{MT}_{1}$ and $\mathrm{MT}_{2}$, new melatonergic ligands possessing novel chemotypes were successfully discovered by screening the ZINC database ${ }^{40,41}$. Therefore, uncovering the features of the ligand-binding site of melatonin receptors has valuable pharmacological significance. In this study, we solved the structures of $\mathrm{MT}_{1}$ and $\mathrm{MT}_{2}$ coupled to $\mathrm{G}_{\mathrm{i}}$ protein, the form representing the active state during receptor signaling. Interestingly, we found that the conserved $\mathrm{H}^{5.46}, \mathrm{~N}^{4.60}$, and $\mathrm{Y}^{5.38}$ positioned around the ligand pocket adopt conformations different from those captured in the inactive state. These varied conformations result in a quite different ligand-binding site and the associated channel to the site. While our manuscript is in submission, Okamoto et al. report the structure of ramelteon- $-\mathrm{MT}_{1}-\mathrm{G}_{\mathrm{i}}$ with varied conformations of $\mathrm{H}^{5.46}, \mathrm{~N}^{4.60}$, and $\mathrm{Y}^{5.38}{ }^{42}$. However, an inspection of their data revealed that the quality of their density map was poor and that the model was incorrectly built, especially in the regions of TM5, TM6, and ICL2 and for the residues of $\mathrm{H}^{5.46}, \mathrm{~N}^{4.60}$, and $\mathrm{Y}^{5.38}$ (Supplementary Fig. 10). Moreover, their map supports the model built here (Supplementary Fig. 10). Together, the distinctive feature of the $\mathrm{MT}_{1}$ ligand site revealed here provides an unrevealed clue for designing novel ligands with $\mathrm{MT}_{1}$ selectivity in the future. To date, the observed ligand-binding pocket in all solved structures is shaped with agonists sharing a melatonin-like chemotype core. However, when binding to the recently identified ligands with a new chemotype, reorganization of the pocket with remarkable differences from the current pocket probably would occur. Such plasticity in the ligand-binding site is also observed in other receptors, such as in the $\mathrm{CB} 1$ receptor $^{36}$. Therefore, further delineating the pocket bound with various ligands will potentially drive a more efficient structure-based drug design.

One of the fundamental questions in the GPCR field is the G protein-coupling selectivity. To date, no general rule guiding GPCR-G-protein assembly has been concluded. For example, although muscarinic receptors share high sequence homology, they display different $\mathrm{G}$ protein-coupling profiles ${ }^{39}$. Similarly, $\mathrm{MT}_{1}$ shares high sequence identity with $\mathrm{MT}_{2}$, but it couples more G-protein subtypes. Here, we revealed that $\mathrm{MT}_{1}$ and $\mathrm{MT}_{2}$ utilize a nearly identical set of residues to engage $G_{i}$. The combined sequence and conformation of the receptor core result in a unique $G_{i}$ binding mode, consistent with the observation of divergent $G_{i}$ conformations in the reported structures. Although ICL2 participates in the interactions with $\mathrm{G}_{\mathrm{i}}$ in almost all the reported structures, it does not play a similar role in $\mathrm{MT}_{1}$ and $\mathrm{MT}_{2}$. However, ICL2 is the only cytoplasmic region where clear differences were observed between $\mathrm{MT}_{1}$ and $\mathrm{MT}_{2}$. Therefore, the ICL2 of $\mathrm{MT}_{1}$ probably confers selective $\mathrm{MT}_{1}$ coupling to $G_{q / 11}$ by generating a special interface different from that used for $\mathrm{G}_{\mathrm{i}}$. Altogether, our study reveals the structural basis of $\mathrm{G}$ protein coupling to melatonin receptors and provides new clues for $\mathrm{MT}_{1}$ and $\mathrm{MT}_{2}$ selective drug design.

\section{Methods}

Constructs and complex expression. The coding sequence of wild-type human $\mathrm{MTNR}_{1} \mathrm{~A}\left(\mathrm{MT}_{1}\right)$ or modified human $\mathrm{MTNR}_{1} \mathrm{~B}\left(\mathrm{MT}_{2}\right)$ was cloned into the pFastbac 
A vector (Thermo Fisher Cat\# 10360014) with a hemagglutinin (HA) signal peptide followed by a FLAG tag at the N-terminus and a hexa-histidine tag at the C-terminus. Three mutations (L108F, F129 W, and C140 L) were introduced into $\mathrm{MT}_{2}$ to improve the protein behavior. Dominant-negative Gail (DNGail) with mutations (G203A and A326S) ${ }^{43}$ was cloned into the pFastbac A vector, and $G \beta_{1} \gamma_{2}$ was cloned into the pFastbac Dual vector. $\mathrm{MT}_{1}, \mathrm{MT}_{2}$, DNGail, and $\mathrm{G}_{1} \gamma_{2}$ were coexpressed in Spodoptera frugiperda Sf9 cells (Invitrogen Cat\# A35243) using the Bac-to-Bac baculovirus expression system (Thermo Fisher Cat\# 10360014). Cells were infected at a density of $4 \times 10^{6}$ cells per $\mathrm{ml}$ with baculoviruses expressing $\mathrm{MT}_{1}$ or $\mathrm{MT}_{2}, \mathrm{DNGail}$, and $\mathrm{G} \beta_{1} \gamma_{2}$ at a ratio of 30:5:1. The infected cells were cultured at $27^{\circ} \mathrm{C}$ for $48 \mathrm{~h}$, collected by centrifugation at $1000 \times g$ for $10 \mathrm{~min}$, and then stored at $-80^{\circ} \mathrm{C}$ for future use.

Complex formation and purification. To obtain the GPCR- $\mathrm{G}_{\mathrm{i}}$ complex, cell pellets were thawed and suspended in lysis buffer (10 mM HEPES, pH 7.5, $0.5 \mathrm{mM}$ EDTA) supplemented with $5 \mu \mathrm{M}$ ramelteon (agonist, MCE Cat\# HY-A0014) or 2-iodomelatonin (agonist, MCE Cat\# HY-101176) and then rotated at $4{ }^{\circ} \mathrm{C}$ for $60 \mathrm{~min}$ to induce the formation of the complexes. Cell membranes were collected and homogenized in solubilization buffer buffer containing $20 \mathrm{mM}$ HEPES $\mathrm{pH}$ 7.5, $100 \mathrm{mM} \mathrm{NaCl}, 5 \mu \mathrm{M}$ agonist, $10 \%$ glycerol, $1 \%$ (w/v) n-Dodecyl-B-D-Maltoside (DDM, Anatrace Cat\# D310), 0.1\% (w/v) cholesteryl hemisuccinate (CHS, Sigma Cat\#C6512), $0.2 \mu \mathrm{g} \mathrm{ml}^{-1}$ leupeptin (Sigma-Aldrich Cat\# L5793), $100 \mu \mathrm{g} \mathrm{ml}^{-1}$ benzamidine (Sigma-Aldrich Cat\# 12072), $10 \mathrm{mM} \mathrm{MgCl}, 5 \mathrm{mM} \mathrm{CaCl}_{2}, 1 \mathrm{mM}$ $\mathrm{MnCl}_{2}, 100 \mu \mathrm{U} \mathrm{ml}^{-1}$ lambda phosphatase (NEB Cat\# P0753S), and $25 \mu \mathrm{U} \mathrm{ml}^{-1}$ apyrase (NEB Cat\# M0398S), and then incubated at $4{ }^{\circ} \mathrm{C}$ for $90 \mathrm{~min}$. The supernatant was isolated by centrifugation at $28,000 \times g$ for $60 \mathrm{~min}$ and incubated with the Anti-FLAG M1 affinity resin (M1 resin, Sigma-Aldrich Cat\# A4596) at $4{ }^{\circ} \mathrm{C}$ for $90 \mathrm{~min}$. M1 resin was then collected and washed with the wash buffer containing $20 \mathrm{mM}$ HEPES pH 7.5, $100 \mathrm{mM} \mathrm{NaCl}, 5 \mu \mathrm{M}$ agonist, $0.1 \% \mathrm{DDM}, 0.01 \% \mathrm{CHS}$, and $2 \mathrm{mM} \mathrm{CaCl}$. Buffer exchange from DDM buffer to lauryl maltose neopentyl glycol (LMNG, Anatrace, Cat\# 4216588) buffer was performed in a stepwise manner. After buffer exchange, the M1 resin was further washed with LMNG buffer containing $20 \mathrm{mM}$ HEPES pH 7.5, $100 \mathrm{mM} \mathrm{NaCl}, 5 \mu \mathrm{M}$ agonist, $0.01 \%$ (w/v) LMNG, $0.001 \%(\mathrm{w} / \mathrm{v}) \mathrm{CHS}$, and $2 \mathrm{mM} \mathrm{CaCl}_{2}$. The complex was eluted with elution buffer containing $20 \mathrm{mM}$ HEPES pH 7.5, $100 \mathrm{mM} \mathrm{NaCl}, 5 \mu \mathrm{M}$ agonist, $0.00075 \%(\mathrm{w} / \mathrm{v})$ LMNG, $0.00025 \%$ (w/v) glycol-diosgenin (GDN, Anatrace Cat\#GDN101), $0.0001 \%$ CHS, $5 \mu \mathrm{M}$ agonist, $5 \mathrm{mM}$ EDTA, and $200 \mu \mathrm{g} \mathrm{ml}^{-1}$ synthesized Flag peptide. The eluted complex was concentrated and incubated with $\mathrm{scFv} 16^{44}$ at a molar ratio of 1:1.5 for $60 \mathrm{~min}$ on ice. The complex was further purified by size-exclusion chromatography using a Superdex 200 Increase 10/300 column (GE Healthcare) pre-equilibrated with buffer containing $20 \mathrm{mM}$ HEPES, pH 7.5, $100 \mathrm{mM} \mathrm{NaCl}$, $0.00075 \%(\mathrm{w} / \mathrm{v})$ LMNG, $0.00025 \%(\mathrm{w} / \mathrm{v})$ GDN, $0.0001 \%(\mathrm{w} / \mathrm{v}) \mathrm{CHS}$, and $5 \mu \mathrm{M}$ agonist. The complex fractions were collected and concentrated to $5 \mathrm{mg} / \mathrm{ml}$ using a $100-\mathrm{kDa}$ molecular weight cutoff concentrator (Millipore) for electron microscopy experiments.

Cryo-grid preparation and EM data collection. To prepare the cryo-EM sample, $3 \mu \mathrm{l}$ purified complex was applied onto the amorphous alloy film grid (M024Au300-R12/13) $)^{45}$ or 100 Holey Carbon film (Au, 300 mesh, N1-C14nAu30-01), glow-discharged by the easiGlow ${ }^{\text {st }}$ Glow Discharge Cleaning System (PELCO, USA) at $15 \mathrm{~mA}$ for $45 \mathrm{~s}$. At $4{ }^{\circ} \mathrm{C}$ and $95 \%$ humidity, the sample was waited for $3 \mathrm{~s}$ and blotted for $2 \mathrm{~s}$. Grids were plunge-frozen in liquid ethane cooled by liquid nitrogen using Vitrobot Mark IV (Thermo Fisher Scientific) and then stored in liquid nitrogen until checked. Movies were collected on a $300 \mathrm{kV}$ Titan Krios Gi3 microscope (Thermo Fisher Scientific FEI, the Kobillka Cryo-EM Center of the Chinese University of Hong Kong, Shenzhen). The raw movies were recorded by a Gatan K3 BioQuantum camera at a magnification of 105,000, and the pixel size was $0.83 \AA$. Inelastically scattered electrons were excluded by a GIF Quantum energy filter (Gatan, USA) using a slit width of $20 \mathrm{eV}$. The movie stacks were acquired with the defocus range of -1.1 to -2.0 micron with a total exposure time of $2.5 \mathrm{~s}$ fragmented into 50 frames $(0.05 \mathrm{~s} /$ frame $)$ and with a dose rate of $21.2 \mathrm{e} / \mathrm{pixel} / \mathrm{s}$. Automated single-particle data acquisition was performed using SerialEM 3.7.

Image processing and 3D reconstructions. Image processing of the 2iodomelatonin- $-\mathrm{MT}_{1}-\mathrm{G}_{\mathrm{i}}$-scFv16 complex was conducted as previously described $^{46,47}$. Briefly, data binned four times were used for micrograph screening and particle picking, and data binned two times were used for particle screening and classification. The particles after initial cleaning were subjected to particle extraction from the originally cleaned micrograph, and the resultant dataset was used for final cleaning and reconstruction. Specifically, raw movie frames were aligned with MotionCor2 using a $9 \times 7$ patch, and the contrast transfer function (CTF) parameters were estimated using Gctf and ctf in JSPR ${ }^{48}$. Only the micrographs with consistent CTF values, including defocus and astigmatism parameters, were kept for subsequent image processing. This process kept 3513 micrographs from 3762 raw movies. Templates for particle selection were generated by projecting the $3 \mathrm{D}$ volume of the V2R-Gs complex ${ }^{49}$. The $3,578,225$ particles picked from template picking were subjected to 2 rounds of $2 \mathrm{D}$ classification, reducing their size to $1,131,706$ and then reducing to 773,176 by $3 \mathrm{D}$ classification. After several rounds of ab initio refinement, the particles kept at 379,512 were subjected to nonuniform refinement for a 3.05 angstrom reconstruction. The image parameters were converted back and to Relion ${ }^{50}$ and cryoSPARC $^{51}$ by use of the pyem package $^{52}$. For the ramelteon- $\mathrm{MT}_{1}-\mathrm{G}_{\mathrm{i}}-\mathrm{scFV} 16$ complex, dose-fractionated image stacks of the collected movies were subjected to beam-induced motion correction using MotionCor2.153, and the CTF parameters for each micrograph were determined by Gct ${ }^{54}$. The 2-iodomelatonin- $\mathrm{MT}_{1}-\mathrm{G}_{\mathrm{i}}$-scFv16 complex was set as the $3 \mathrm{D}$ template for autopicking, and 2,074,844 particles were picked in RELION 3.055. Four cycles of 2D classification were performed. After 2D classification, the particles with good features were further subjected to initial model building and 3D classification. Finally, 4,741,844 particles were further subjected to Bayesian particle polishing and CTF refinement. During postprocessing, different masks were applied on the global refinement map, and a map with a global resolution of $3.33 \AA$ (FSC $=0.143$ ) was obtained. To improve the map quality, the particles were transferred to cryoSPARC for homogeneous and nonuniform refinement. Finally, a density map was obtained with a global resolution of $3.29 \AA(F S C=0.143)$. Estimation of the local resolution was performed in cryoSPARC. For the ramelteon$\mathrm{MT}_{2}-\mathrm{G}_{\mathrm{i}}-\mathrm{scFv} 16$ complex, 4609 movies were collected and processed by cryoSPARC v.3.2.056. Beam-induced motion correction was performed using patch motion correction, and contrast transfer function (CTF) parameters were estimated by patch CTF estimation in cryoSPARC. Templates for particle selection were generated by projecting the $3 \mathrm{D}$ volume of the ramelteon- $\mathrm{MT}_{1}-\mathrm{G}_{\mathrm{i}}-\mathrm{scFV} 16$ complex. A total of 5,234,455 particles were selected by autopicking (particle diameter set as $150 \AA$ and Lowpass filter as $20 \AA$ ) as well as inspection picks, and they were then subjected to $2 \mathrm{D}$ classification. Three cycles of $2 \mathrm{D}$ classification yielded 847,573 particles with clear features. Six initial models were built by ab initio reconstruction. After that, 639,905 particles based on three 3D classes were selected for homogenous refinement in cryoSPARC. To improve the map quality, local refinement and sharpening were performed using the local refinement calculated B-factor. Finally, a density map was obtained with a global resolution of $3.5 \AA$ (determined by gold standard FSC using the 0.143 criteria). Estimation of the loca resolution was performed in cryoSPARC using the volume and mask of the local refinement output.

Model building, refinement, and computational docking. To build the 2iodomelatonin- $\mathrm{MT}_{1}-\mathrm{G}_{\mathrm{i}}-\mathrm{scFv} 16$ complex, the crystal structure of 2-iodomelatonin bound $\mathrm{MT}_{1}$ (PDB 6ME4) was used as the starting model. To build the ramelteon$\mathrm{MT}_{1}-\mathrm{G}_{\mathrm{i}}$-scFv16 complex, the built 2-iodomelatonin- $\mathrm{MT}_{1}-\mathrm{G}_{\mathrm{i}}$ cryo-EM structure and ramelteon- $\mathrm{MT}_{1}$ crystal structure (PDB 6ME2) were used as the guiding models. For the ramelteon- $\mathrm{MT}_{2}-\mathrm{G}_{\mathrm{i}}$-scFv16 complex, the 2-iodomelatonin- $\mathrm{MT}_{1}-\mathrm{G}_{1}$ and ramelteon- $\mathrm{MT}_{2}$ structures (PDB 6ME9) were used as the guiding models. For the $\mathrm{G}$ protein in the three complexes, the Gi heterotrimer from the FPR2-Gi cryoEM structure (PDB 6OMM) was used as the initial model. All the models were first docked into the EM density map using Chimera ${ }^{57}$, followed by iterative manual adjustment and rebuilding in COOT $^{58}$ and phenix.real_space_refine in Phenix ${ }^{59}$. The final model statistics were validated using MolProbity ${ }^{60}$. The molecular graphic figures were prepared with UCSF Chimera, UCSF ChimeraX ${ }^{61}$, and PyMOL Docking of 5-HEAT and CTL 01-05-B-A05 to melatonin receptors was performed using AutoDock Vina ${ }^{62}$. Receptor or ligand structures were optimized using AutoDockTools-1.5.6. We set a $25 \times 25 \times 35 \AA^{3}$ box as the search region, as such a size was large enough for ligand binding. The outputs of the autodock were analyzed with PyMOL.

Pocket diameter determination. Channel dimensions were obtained using CAVER analyst v3.0.3 $3^{63}$. Before performing the calculation, hydrogens were added to the corresponding coordinates using PyMOL. The region around the perceived channel entrance was manually set as the starting point of the tunnel. Using default program parameters, channel dimensions were extracted and trimmed to the segment between the channel entrance and ligand centroid. For visual comparison and comprehension, the section view prepared with PyMOL is shown.

cAMP assay. G-protein activation was measured using the cAMP-Gi KIT (cisbio, 62AM9PEB). The day before transfection, HEK293 cells (ATCC CRL-1573) were seeded at a density of $0.8 \times 10^{6}$ cells per well in 6 -well culture plates and incubated at $37^{\circ} \mathrm{C}$ with $5 \% \mathrm{CO}$. Cells were transiently transfected with plasmids coding the wild-type melatonin receptor or mutant receptor using Lipo8000 (Beyotime, C0533). Twenty-four hours posttransfection, the culture media was removed, and the cells were washed with PBS buffer. The transfected HEK293 cells were then plated into white 384-well plates (4000/well) in stimulation buffer and treated with $20 \mu \mathrm{M}$ forskolin, $500 \mu \mathrm{M}$ IBMX, and test agonist for $30 \mathrm{~min}$. After that, $5 \mu \mathrm{L}$ cAMP Eu-cryptate reagent and $5 \mu \mathrm{l}$ anti-cAMP-d2 working solution were added ${ }^{64}$. After incubation at room temperature for $1 \mathrm{~h}$, fluorescence was acquired at $620 / 665 \mathrm{~nm}$ using a FRET reader (PCLARIOstar Plus) ${ }^{65}$ and analyzed with OriginPro 2021. The expression level of each construct was determined by flow cytometry analysis and was used to normalize the cAMP level. Specifically, transfected cells were labeled with DYKDDDDK Tag (D6W5B) Rabbit mAb (cell signaling technology, 15009S), and then washed with PBS. Cells were resuspended in ice-cold PBS, and the fluorescent intensity of single cells was quantified by CytoFLEX (Beckman) flow cytometer equipped with a $488 \mathrm{~nm}$ laser. The flow cytometry data were recorded and analyzed with CytExpert 2.3.0.84. Values of mean fluorescence 
intensity from $\sim 20,000$ cells per sample were used for analysis. Statistical analysis was performed with either one-way analysis of variance and a Dunnetts post-test or a paired $t$-test, and significance accepted at $P<0.05$.

Reporting summary. Further information on research design is available in the Nature Research Reporting Summary linked to this article.

\section{Data availability}

The data that support this study are available from the corresponding authors upon reasonable request. The density maps and structure coordinates have been deposited to the Electron Microscopy Database (EMDB) and the protein data bank (PDB) with the following accession codes: EMD-31980 and 7VGY for the 2-iodomelatonin- $\mathrm{MT}_{1}-\mathrm{G}_{\mathrm{i}^{-}}$ scFv16 complex; EMD-31981 and 7VGZ for the ramelteon- $\mathrm{MT}_{1}-\mathrm{G}_{\mathrm{i}}-\mathrm{scFV} 16$ complex; and EMD-31982 and 7VH0 for the ramelteon- $\mathrm{MT}_{2}-\mathrm{G}_{\mathrm{i}}$-scFV16 complex. The PDB datasets used for analysis in this study include 6ME2, 6ME4, 6ME9, 7DB6, 6OMM, 7JVR, 6OSA, 6N4B, 7JJO, 7JV5, and 7AUE).

Received: 15 September 2021; Accepted: 5 January 2022; Published online: 24 January 2022

\section{References}

1. Reppert, S. M., Weaver, D. R. \& Ebisawa, T. Cloning and characterization of a mammalian melatonin receptor that mediates reproductive and circadian responses. Neuron 13, 1177-1185 (1994).

2. Reppert, S. M. et al. Molecular characterization of a second melatonin receptor expressed in human retina and brain: the Mellb melatonin receptor. Proc. Natl Acad. Sci. USA 92, 8734-8738 (1995).

3. Dubocovich, M. L. et al. International Union of Basic and Clinical Pharmacology. LXXV. Nomenclature, classification, and pharmacology of G protein-coupled melatonin receptors. Pharmacol. Rev. 62, 343-380 (2010).

4. Brzezinski, A. Melatonin in humans. N. Engl. J. Med. 336, 186-195 (1997).

5. Ganguly, S., Coon, S. L. \& Klein, D. C. Control of melatonin synthesis in the mammalian pineal gland: the critical role of serotonin acetylation. Cell Tissue Res. 309, 127-137 (2002).

6. Brown, G. M. Light, melatonin and the sleep-wake cycle. J. Psychiatry Neurosci. 19, 345-353 (1994).

7. Sewerynek, E. Melatonin and the cardiovascular system. Neuro Endocrinol. Lett. 23, 79-83 (2002).

8. Carrillo-Vico, A., Lardone, P. J., Alvarez-Sanchez, N., Rodriguez-Rodriguez, A. \& Guerrero, J. M. Melatonin: buffering the immune system. Int. J. Mol. Sci. 14, 8638-8683 (2013).

9. Liu, J. et al. MT1 and MT2 melatonin receptors: a therapeutic perspective. Annu. Rev. Pharmacol. Toxicol. 56, 361-383 (2016).

10. Grant, S. G., Melan, M. A., Latimer, J. J. \& Witt-Enderby, P. A. Melatonin and breast cancer: cellular mechanisms, clinical studies and future perspectives. Expert. Rev. Mol. Med. 11, e5 (2009).

11. Cardinali, D. P., Ladizesky, M. G., Boggio, V., Cutrera, R. A. \& Mautalen, C. Melatonin effects on bone: experimental facts and clinical perspectives. J. Pineal Res. 34, 81-87 (2003).

12. Karamitri, A. \& Jockers, R. Melatonin in type 2 diabetes mellitus and obesity. Nat. Rev. Endocrinol. 15, 105-125 (2019).

13. Cecon, E., Oishi, A. \& Jockers, R. Melatonin receptors: molecular pharmacology and signalling in the context of system bias. Br. J. Pharmacol. 175, 3263-3280 (2018).

14. Brydon, L. et al. Dual signaling of human Mel1a melatonin receptors via G(i2), G(i3), and G(q/11) proteins. Mol. Endocrinol. 13, 2025-2038 (1999).

15. Lacoste, B. et al. Anatomical and cellular localization of melatonin MT1 and MT2 receptors in the adult rat brain. J. Pineal Res. 58, 397-417 (2015).

16. Waly, N. E. \& Hallworth, R. Circadian pattern of melatonin MT1 and MT2 receptor localization in the rat suprachiasmatic nucleus. J. Circadian Rhythms 13, 1 (2015).

17. Gobbi, G. \& Comai, S. Differential function of melatonin MT1 and MT2 receptors in REM and NREM sleep. Front. Endocrinol. (Lausanne) 10, 87 (2019).

18. Comai, S., Ochoa-Sanchez, R. \& Gobbi, G. Sleep-wake characterization of double MT(1)/MT(2) receptor knockout mice and comparison with MT(1) and MT(2) receptor knockout mice. Behav. Brain Res. 243, 231-238 (2013).

19. Ochoa-Sanchez, R. et al. Promotion of non-rapid eye movement sleep and activation of reticular thalamic neurons by a novel MT2 melatonin receptor ligand. J. Neurosci. 31, 18439-18452 (2011).

20. Kato, K. et al. Neurochemical properties of ramelteon (TAK-375), a selective MT1/MT2 receptor agonist. Neuropharmacology 48, 301-310 (2005).
21. Rajaratnam, S. M. et al. Melatonin agonist tasimelteon (VEC-162) for transient insomnia after sleep-time shift: two randomised controlled multicentre trials. Lancet 373, 482-491 (2009).

22. Manikandan, S. Agomelatine: a novel melatonergic antidepressant. J. Pharmacol. Pharmacother. 1, 122-123 (2010).

23. Zlotos, D. P., Jockers, R., Cecon, E., Rivara, S. \& Witt-Enderby, P. A. MT1 and MT2 melatonin receptors: ligands, models, oligomers, and therapeutic potential. J. Med. Chem. 57, 3161-3185 (2014).

24. Boutin, J. A., Witt-Enderby, P. A., Sotriffer, C. \& Zlotos, D. P. Melatonin receptor ligands: a pharmaco-chemical perspective. J. Pineal Res. 69, e12672 (2020).

25. Jockers, R. et al. Update on melatonin receptors: IUPHAR Review 20. Br. J. Pharmacol. 173, 2702-2725 (2016).

26. Dubocovich, M. L. \& Takahashi, J. S. Use of 2-[125I]iodomelatonin to characterize melatonin binding sites in chicken retina. Proc. Natl Acad. Sci. USA 84, 3916-3920 (1987).

27. Stauch, B. et al. Structural basis of ligand recognition at the human MT1 melatonin receptor. Nature 569, 284-288 (2019).

28. Johansson, L. C. et al. XFEL structures of the human MT2 melatonin receptor reveal the basis of subtype selectivity. Nature 569, 289-292 (2019).

29. Mazna, P. et al. The role of proline residues in the structure and function of human MT2 melatonin receptor. J. Pineal Res. 45, 361-372 (2008).

30. Chan, K. H., Tse, L. H., Huang, X. \& Wong, Y. H. Molecular basis defining the selectivity of substituted isoquinolinones for the melatonin MT2 receptor. Biochem. Pharmacol. 177, 114020 (2020).

31. Nonno, R. et al. A new melatonin receptor ligand with mt1-agonist and MT2 antagonist properties. J. Pineal Res. 29, 234-240 (2000).

32. Wang, J., Hua, T. \& Liu, Z. J. Structural features of activated GPCR signaling complexes. Curr. Opin. Struct. Biol. 63, 82-89 (2020).

33. Kokkola, T., Salo, O. M., Poso, A. \& Laitinen, J. T. The functional role of cysteines adjacent to the NRY motif of the human MT1 melatonin receptor. J. Pineal Res. 39, 1-11 (2005).

34. Koehl, A. et al. Structure of the micro-opioid receptor-Gi protein complex. Nature 558, 547-552 (2018)

35. Zhuang, Y. et al. Structural insights into the human D1 and D2 dopamine receptor signaling complexes. Cell 184, 931-942 e18 (2021).

36. Krishna Kumar, K. et al. Structure of a signaling cannabinoid receptor 1-G protein complex. Cell 176, 448-458 e12 (2019).

37. Kato, H. E. et al. Conformational transitions of a neurotensin receptor 1-Gi1 complex. Nature 572, 80-85 (2019).

38. Bonnefond, A. et al. Rare MTNR1B variants impairing melatonin receptor $1 \mathrm{~B}$ function contribute to type 2 diabetes. Nat. Genet. 44, 297-301 (2012).

39. Maeda, S., Qu, Q., Robertson, M. J., Skiniotis, G. \& Kobilka, B. K. Structures of the M1 and M2 muscarinic acetylcholine receptor/G-protein complexes. Science 364, 552-557 (2019).

40. Patel, N. et al. Structure-based discovery of potent and selective melatonin receptor agonists. Elife 9, https://doi.org/10.7554/eLife.53779 (2020).

41. Stein, R. M. et al. Virtual discovery of melatonin receptor ligands to modulate circadian rhythms. Nature 579, 609-614 (2020).

42. Okamoto, H. H. et al. Cryo-EM structure of the human MT1-Gi signaling complex. Nat. Struct. Mol. Biol. 28, 694-701 (2021).

43. Liu, P. et al. The structural basis of the dominant negative phenotype of the G alpha(i1)beta(1)gamma(2) G203A/A326S heterotrimer. Acta Pharmacol. Sin. 37, 1259-1272 (2016).

44. Koehl, A. et al. Structure of the mu-opioid receptor-G(i) protein complex. Nature 558, 547 (2018).

45. Huang, X. J. et al. Amorphous nickel titanium alloy film: a new choice for cryo electron microscopy sample preparation. Prog. Biophys. Mol. Biol. 156, 3-13 (2020).

46. Liu, Z. et al. Determination of the ribosome structure to a resolution of 2.5 angstrom by single-particle cryo-EM. Protein Sci. 26, 82-92 (2017).

47. Liu, Z., Guo, F., Wang, F., Li, T. C. \& Jiang, W. 2.9 angstrom resolution CryoEM 3D reconstruction of close-packed virus particles. Structure 24, 319-328 (2016).

48. Jiang, W., Guo, F. \& Liu, Z. A graph theory method for determination of cryoEM image focuses. J. Struct. Biol. 180, 343-351 (2012).

49. Wang, L. et al. Cryo-EM structure of the AVP-vasopressin receptor 2-G(s) signaling complex. Cell Res. https://doi.org/10.1038/s41422-021-00483-Z (2021).

50. Scheres, S. H. RELION: implementation of a Bayesian approach to cryo-EM structure determination. J. Struct. Biol. 180, 519-530 (2012).

51. Punjani, A., Rubinstein, J. L., Fleet, D. J. \& Brubaker, M. A. cryoSPARC: algorithms for rapid unsupervised cryo-EM structure determination. Nat. Methods 14, 290-296 (2017).

52. Asarnow, D., Palovcak, E. \& Cheng, Y. asarnow/pyem: UCSF pyem v0.5. https://github.com/asarnow/pyem/ (2019). 
53. Zheng, S. Q. et al. MotionCor2: anisotropic correction of beam-induced motion for improved cryo-electron microscopy. Nat. Methods 14, 331-332 (2017).

54. Zhang, K. Gctf: Real-time CTF determination and correction. J. Struct. Biol. 193, 1-12 (2016).

55. Scheres, S. H. W. RELION: Implementation of a Bayesian approach to cryoEM structure determination. J. Struct. Biol. 180, 519-530 (2012).

56. Punjani, A., Rubinstein, J. L., Fleet, D. J. \& Brubaker, M. A. cryoSPARC: algorithms for rapid unsupervised cryo-EM structure determination. Nat. Methods 14, 290 (2017).

57. Pettersen, E. F. et al. UCSF chimera-a visualization system for exploratory research and analysis. J. Comput. Chem. 25, 1605-1612 (2004).

58. Emsley, P. \& Cowtan, K. Coot: model-building tools for molecular graphics. Acta Crystallogr. Sec. D Struct. Biol. 60, 2126-2132 (2004).

59. Adams, P. D. et al. PHENIX: a comprehensive Python-based system for macromolecular structure solution. Acta Crystallogr. Sec. D Struct. Biol. 66, 213-221 (2010).

60. Chen, V. B. et al. MolProbity: all-atom structure validation for macromolecular crystallography. Acta Crystallogr. Sec. D Struct. Biol. 66, 12-21 (2010).

61. Goddard, T. D. et al. UCSF ChimeraX: meeting modern challenges in visualization and analysis. Protein Sci. 27, 14-25 (2018).

62. Trott, O. \& Olson, A. J. Software news and update AutoDock Vina: improving the speed and accuracy of docking with a new scoring function, efficient optimization, and multithreading. J. Comput. Chem. 31, 455-461 (2010).

63. Chovancova, E. et al. CAVER 3.0: a tool for the analysis of transport pathways in dynamic protein structures. PLoS Comput. Biol. 8, e1002708 (2012).

64. Qiao, A. N. et al. Structural basis of $\mathrm{G}(\mathrm{s})$ and $\mathrm{G}(\mathrm{i})$ recognition by the human glucagon receptor. Science 367, 1346 (2020).

65. Hua, T. et al. Activation and signaling mechanism revealed by cannabinoid receptor-G(i) complex structures. Cell 180, 655 (2020).

\section{Acknowledgements}

The cryo-EM data were collected at the Kobilka Cryo-EM Microscopy Center, Chinese University of Hong Kong (ShenZhen). We thank the Core Facility Center for Life Sciences of the University of Science and Technology of China for their help with functional assays. This work was supported by National Key Research and Development Program of China Grants 2017YFA0503600 (to M.T.), and Chinese National Natural Science Foundation Grants 31770895 (to Y.T.), U1732114 (to X.L.).

\section{Author contributions}

Q.W. prepared the protein samples, helped with cryo-grids preparation and cryo-EM grid screening and data collection, processed the cryo-EM data of the ramelteon- $\mathrm{MT}_{2}-\mathrm{G}_{\mathrm{i}}$-scFv16 complex, built the models and refined the structures, performed the functional assays and docking studies, and helped with the manuscript preparation. Q.L. prepared cryo-grids, performed cryo-EM grid screening and data collection, and processed the cryo-EM data of the ramelteon-MT $-\mathrm{G}_{1}-\mathrm{scFv} 16$ complex. Q.G., M.T., Q.Go., and X.L. helped with data analysis and interpretation. Y.D. helped with sample preparation and data collection. Z.L. processed the cryo-EM data of the 2-iodomelatonin- $\mathrm{MT}_{1}-\mathrm{G}_{\mathrm{i}}-\mathrm{scFv} 16$ complex and helped with data analysis and interpretation. Y.T. conceived and designed the overall project, built the models and refined the structures, supervised the research, and wrote the manuscript with input from all co-authors.

\section{Competing interests}

The authors declare no competing interests.

\section{Additional information}

Supplementary information The online version contains supplementary material available at https://doi.org/10.1038/s41467-022-28111-3.

Correspondence and requests for materials should be addressed to Yang Du, Zheng Liu or Yuyong Tao.

Peer review information Nature Communications thanks Matthew Belousoff and the other, anonymous, reviewer(s) for their contribution to the peer review of this work.

Reprints and permission information is available at http://www.nature.com/reprints

Publisher's note Springer Nature remains neutral with regard to jurisdictional claims in published maps and institutional affiliations.

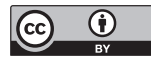

Open Access This article is licensed under a Creative Commons Attribution 4.0 International License, which permits use, sharing, adaptation, distribution and reproduction in any medium or format, as long as you give appropriate credit to the original author(s) and the source, provide a link to the Creative Commons license, and indicate if changes were made. The images or other third party material in this article are included in the article's Creative Commons license, unless indicated otherwise in a credit line to the material. If material is not included in the article's Creative Commons license and your intended use is not permitted by statutory regulation or exceeds the permitted use, you will need to obtain permission directly from the copyright holder. To view a copy of this license, visit http://creativecommons.org/ licenses/by/4.0/.

(C) The Author(s) 2022 